\title{
Metacognição no processo de letramento informacional
}

\author{
Kelley Cristine Gonçalves Dias Gasque
}

Resumo: O artigo apresenta revisão de literatura sobre a metacognição no âmbito do letramento informacional. A metacognição diz respeito ao conhecimento do conhecimento e ao controle sobre esse processo. Por sua vez, o LI relaciona-se à aprendizagem sobre como buscar, usar e comunicar a informação. A análise dos artigos identifica poucos artigos sobre a temática, o que requer mais investimentos em pesquisas na área, reconhecendo o potencial da metacognição para potencializar a aprendizagem de LI. Sugerem-se estratégias metacognitivas para o ensino dos padrões de LI. As estratégias metacognitivas fundamentam-se em três funções - planejamento, monitoração e avaliação. Os aprendizes precisam desenvolver a capacidade para refletir sobre o próprio processo de busca e uso da informação - LI - conhecer e saber sobre o quê, quando, como e por que realizam as atividades de busca e uso da informação, bem como usar as estratégias de intervenção.

Palavras-chave: Metacognição. Letramento informacional. Aprendizagem. Busca e uso da informação.

\section{INTRODUÇÃO}

Nos últimos anos, observa-se uma preocupação enorme com a aprendizagem, em especial com o aprender a aprender. Bransford, Brown e Cocking (2007) ao revisarem a literatura educacional mostram que a experiência, o conhecimento factual e a metacognição são os fatores que mais influenciam a aprendizagem. Ao considerar o letramento informacional como processo de aprendizagem necessário para a aquisição de competências para lidar eficaz e eficientemente com a informação (GASQUE, 2012), o objetivo deste artigo centra-se na contribuição da metacognição no processo de letramento informacional.

Tulvin (1994 apud METCALFE; SHIMAMURA, 1994), no prefácio da obra "Metacognition: knowing about knowing", explica que estudos mostram que os seres humanos conhecem muito mais sobre o conhecer e que podem identificar tipos diferentes de conhecimento e maneiras de conhecer. A metacognição compreende a capacidade de 
reflexão do indivíduo sobre os próprios processos de pensamento, em especial, o processo de construção de conhecimento.

De acordo com Flavell (1979), os estudiosos da aprendizagem ressaltam a contribuição da metacognição na comunicação oral, compreensão oral e da leitura, escrita, aquisição de linguagem, atenção, memória, resolução de problemas, cognição social, e, vários tipos de autocontrole e autoinstrução. Isso porque, de acordo com Bransford, Brown e Cocking (2007), os aprendizes podem aprender estratégias cognitivas com a finalidade de melhorar a compreensão da informação, de perceber as lacunas e preenchê-las, bem como de ativar o conhecimento prévio, de planejar e de dividir o tempo e a memória.

Sobre isso, vale destacar que o uso das estratégias metacognitivas pode potencializar o processo de letramento informacional, na medida em que permite o distanciamento da ação para analisá-la e modificá-la. Compreendem-se estratégias metacognitivas como ferramentas auxiliares do aprendiz para tomada de consciência e autoregulação da própria aprendizagem (ALLUEVA, 2002).

Para tanto, realizou-se revisão de literatura do tipo narrativa (CORDEIRO et al. 2007). Esse tipo de revisão apresenta temática mais aberta e sem pretensões de ser exaustiva. Em geral, não parte de uma questão bem definida, além disso, não exige protocolo rígido para o desenvolvimento da pesquisa. Neste caso, a busca das fontes de informação é mais flexível e menos abrangente. A revisão abrange os conceitos de metacognição e letramento informacional.

\section{METACOGNIÇÃO}

As primeiras atividades de pesquisas sobre metacognição, como tópico de pesquisa próprio, possuem raízes na tese de doutorado de Harts, sobre o sentimento do saber, defendida em Stanford, em 1965 (TULVIN, 1994 apud METCALFE; SHIMAMURA, 1994). Contudo, muitos pesquisadores consideram que a década de 1970 foi o ponto de partida, quando Flavell e colaboradores desenvolveram os primeiros estudos relacionados com a metacognição, nomeadamente com a metamemória. Com 
base nesses estudos, Flavell e Wellman (1977 apud RIBEIRO, 2003) mostram evidências que o conhecimento metacognitivo se desenvolve por meio da consciência do aprendiz sobre o modo como determinadas variáveis podem influenciar o desempenho cognitivo (RIBEIRO, 2003).

De acordo com Portilho (2006), a expressão ‘o cachorro é um mamífero’ referese ao conhecimento declarativo, resultante de uma informação previamente armazenada na memória de alguém. Porém, a expressão 'eu gosto de cinema' relaciona-se ao mundo interior do indivíduo, ao conhecimento procedimental sobre o próprio conhecimento. Nesse caso, pode-se falar de metacognição.

As modalidades de metacognição abrangem a metamemória, meta-atenção, metacompreensão e o metapensamento (ALLUEVA, 2002). Contudo, pode se observar maior ênfase nas pesquisas relacionadas à metamemória, em especial, nas atividades de leitura. Bransford, Brown e Cocking (2007) explicam que a metacognição assume forma de um diálogo interior. Em uma pesquisa com especialistas, eles foram solicitados a externar o próprio pensamento ao longo da realização de uma tarefa. Observou-se que os especialistas monitoravam a própria compreensão para identificar lacunas no conhecimento, melhorar a compreensão da leitura, ativar o conhecimento prévio, bem como ratear tempo e memória.

Nas últimas décadas, o termo metacognição foi amplamente utilizado sem haver consenso sobre o significado teórico do conceito. Isso dificulta tanto a definição quanto a compreensão dos fatores e processos metacognitivos (ANDRETTA, et al. 2010). Entretanto, para Dantas e Rodrigues (2013) pode se perceber uma convergência nas várias definições de metacognição. $\mathrm{O}$ ponto em comum relaciona-se à identificação da metacognição como o comportamento do aprendiz inter-relacionado com o conhecimento. Isso envolve a percepção do objeto e de si e o controle dos recursos - o automonitoramento.

Ribeiro (2002) argumenta que, no domínio educacional o entendimento da metacognição abrange, em geral: (1) conhecimento sobre o conhecimento - consciência dos processos e das competências para a realização da tarefa; e (2) controle ou 
autoregulação - capacidade para avaliar o desenvolvimento da tarefa e corrigi-las se necessário. No entanto, embora possuam diferentes fontes e diferentes problemas, o conhecimento e a regulação da cognição encontram-se intimamente relacionados.

Em uma revisão não sistemática realizada por Andretta et al. (2010), há o reconhecimento de que o processo metacognitivo é diferente para cada indivíduo. A capacidade metacognitiva relaciona-se diretamente com as habilidades de aprendizagem, possibilitando otimizar o tempo e a qualidade do estudo. O estudo apresenta a necessidade de futuras pesquisas no âmbito educacional para aprimorar a relação ensino/aprendizagem.

Stedile e Friendlander (2003) apontam que a metacognição constitui-se uma estratégia possível para desenvolver a autonomia necessária para a vida profissional. Pensar sobre a aprendizagem e estabelecer estratégias para auxiliar esse processo maximizam as potencialidades individuais para a resolução de problemas. Mais ainda, para Brown (1978), saber avaliar as dificuldades e lacunas de conhecimento possibilita a superação dos obstáculos, muitas vezes, por meio de inferências feitas a partir daquilo que se sabe. Portanto, destaca-se a importância não só sobre aquilo que se sabe, mas também, sobre aquilo que não se sabe. Isto é, evita-se assim a ignorância secundária, designação para o não saber que não se sabe (RIBEIRO, 2003).

\section{LETRAMENTO INFORMACIONAL E METACOGNIÇÃO}

O letramento informacional refere-se à aprendizagem de conteúdos relacionados à busca e ao uso da informação, nomeadamente, a identificação da necessidade de informação, o acesso e a avaliação da informação, bem como a organização, o uso e a comunicação da informação (GASQUE, 2012). Portanto, o LI como processo de aprendizagem envolve questões relacionadas ao âmbito psicopedagógico, neurológico, didático, dentre outros. Isso mostra a necessidade de discutir sobre como melhorar a aprendizagem desses conteúdos. Nesse contexto, a metacognição constitui-se um dos 
elementos que possibilita refletir, avaliar e mudar, se necessário, a maneira como se aprende.

Bowler (2010) afirma que a metacognição é um elemento essencial no processo de LI, contudo identifica a escassez de estudos que analisam o conhecimento metacognitivo, especificamente, em relação à busca de informações. De acordo com a autora, esse é um fato, no mínimo irônico, visto que o foco educacional vigente no letramento da informação é muito intenso.

De acordo com Madden et al. (2012), um dos primeiros pesquisadores a apresentar resultados de pesquisa na ciência da informação foi Moore, em 1995, que examinou as estratégias cognitivas e metacognitivas utilizadas pelos estudantes para buscar recursos para as tarefas. Portanto, observa-se a existência de uma lacuna de aproximadamente 30 anos entre o surgimento dos primeiros trabalhos em Psicologia e na Ciência da Informação.

Ao realizar buscas no portal da CAPES, em outubro de 2016, com os descritores “metacognition" e "information literacy" foram encontrados 43 resultados. Destes 37 artigos foram revisados pelos pares. Porém, desse total foram encontrados uma tese, artigos repetidos e muitos que abordavam o conceito de metacognição superficialmente, isto é, sem que o foco fosse a relação entre metacognição e letramento informacional. A análise de cada artigo resultou na identificação de cinco artigos mais relevantes e disponíveis publicados nos últimos 10 anos - a partir de 2006, descritos por título, autor, palavras-chaves e ano de publicação, apresentados no Quadro 1. 
Quadro 1: Levantamento de artigos sobre metacognição e letramento informacional

\begin{tabular}{|c|c|c|c|}
\hline Título & Autor & Assunto & Ano \\
\hline $\begin{array}{l}\text { Seeking and finding - authentic } \\
\text { inquiry models for our evolving } \\
\text { information landscape. }\end{array}$ & $\begin{array}{l}\text { JACOBSON, Trudi; } \\
\text { O'KEEFFE; Emer. }\end{array}$ & $\begin{array}{l}\text { Information literacy; inquiry } \\
\text { models; seeking information; } \\
\text { metacognition. }\end{array}$ & 2014 \\
\hline $\begin{array}{l}\text { Theoretical foundations for } \\
\text { information literacy: a plan for } \\
\text { action. }\end{array}$ & $\begin{array}{l}\text { BUDD, John; LLOYD, } \\
\text { A. }\end{array}$ & $\begin{array}{l}\text { Letramento } \quad \text { informacional; } \\
\text { autonomia; } \\
\text { Paineis. }\end{array}$ & 2014 \\
\hline $\begin{array}{l}\text { Metacognition and web } \\
\text { credibility. }\end{array}$ & MADDEN, Andrew. & $\begin{array}{lr}\text { Pesquisa de informação; } \\
\text { internet; web; classificação de } \\
\text { websites; } \\
\text { informacional. letramento }\end{array}$ & 2012 \\
\hline $\begin{array}{l}\text { Cornering the information } \\
\text { market: metacognition and the } \\
\text { library. }\end{array}$ & $\begin{array}{l}\text { SANTAMARIA, } \\
\text { Michele ; PETRIK, } \\
\text { Denise. }\end{array}$ & $\begin{array}{l}\text { Letramento informacional; } \\
\text { teoria educacional; aspectos } \\
\text { cognitivos; treinamento de } \\
\text { usuário. }\end{array}$ & 2012 \\
\hline $\begin{array}{l}\text { A taxonomy of an adolescent } \\
\text { metacognitive knowledge } \\
\text { during information search } \\
\text { process. }\end{array}$ & BOWLER, Leanne. & $\begin{array}{l}\text { Metacognition; information } \\
\text { search process; taxonomy. }\end{array}$ & 2010 \\
\hline
\end{tabular}

Fonte: elaboração própria

A análise dos artigos mostra que há poucas pesquisas no âmbito da Ciência da Informação e ainda menor quantidade de pesquisas no que concerne ao letramento informacional. O primeiro artigo analisado, de Jacobson e O`Keeffe (2014), trata de um ensaio sobre modelos de questionamentos no cenário informacional, com objetivo de discutir sobre ferramentas para avaliar a informação criticamente, incluindo conteúdos dinâmicos e on-line que mudam e evoluem constantemente, tais como preprints, blogs e wikis.

O segundo artigo, resultado de um painel, considera o LI uma importante atividade do ensino superior, mas subutilizada como processo e caminho para um produto. Assim, são apresentadas quatro possibilidades para um arcabouço conceitual, em que uma delas 
relaciona-se à necessidade de mais estudos sobre a metacognição, reconhecida como estratégia adequada aos processos de LI, que possibilita aos estudantes o envolvimento em reflexões sobre as próprias formas de pensar questões e problemas (BUDD; LLOYD, 2014).

O terceiro artigo, de Madden et al (2012), apresenta resultado de pesquisa qualitativa com estudantes da pós-graduação ao usar a metacognição na avaliação de websites durante a busca da informação. Os estudantes foram incentivados a "pensar em voz alta", como procuraram informações e explicar as ações e estratégias nesse processo. Foram identificados vários critérios utilizados para avaliação. Os critérios foram aplicados em diferentes fases do processo de busca e demonstram variados graus de metacognição. Alguns fatores identificados que afetam a avaliação incluem: o objetivo da pesquisa, conselhos recebidos de professores, bem como a percepção sobre natureza do site.

O relato de experiência de Santamaria e Petrik (2012) parte do pressuposto que os estudantes possuem dificuldades para buscar informações de qualidade na internet. Às vezes, eles sabem usar as estratégias básicas, mas não conseguem avançar, porque não sabem como perguntar sobre o que mais existe ou não entendem como isso se aplica a eles. Nesse sentido, os bibliotecários podem auxiliar os estudantes no desenvolvimento das habilidades metacognitivas, que permitem avaliar realisticamente o que o estudante sabe e não sabe. Assim, as bibliotecas podem ser lugares onde os estudantes, a partir do conhecimento prévio, podem aprender a coletar e organizar as informações.

Por último, Bowler (2010) realizou estudo de caso com a utilização de métodos naturalistas para investigar o conhecimento metacognitivo de adolescentes durante o processo de busca, seleção e uso da informação para um projeto de pesquisa sobre a história da civilização ocidental. Ela descobriu que, apesar de todos os estudantes terem sido orientados pelo conhecimento metacognitivo durante o processo de pesquisa, a natureza desse conhecimento era incompleto e imperfeito. 
Como se observa pelos resultados apresentados, a busca no portal da CAPES apresenta poucos estudos sobre metacognição no âmbito do LI. Isso mostra a necessidade de investir intensivamente nesse tópico de conhecimento, visto que pessoas com habilidades metacognitivas desenvolvidas possuem desempenho superior nas atividades de aprendizagem. Considerando essa questão, o próximo tópico busca oferecer direcionamento para o desenvolvimento de habilidades metacognitivas no processo de letramento informacional.

\section{O USO DO CONCEITO DE METACOGNIÇÃO NO ENSINO- APRENDIZAGEM DE LI}

Muitas vezes, os estudantes realizam atividades sem compreensão do que está implicado na ação em termos de saber ou procedimentos. Compreender requer lucidez e consciência sobre o que e como se faz (PERRAUDEAU, 2009). A metacognição relaciona-se, grosso modo, à reflexão e à avaliação sobre o próprio conhecimento e ao uso das estratégias cognitivas. De acordo com Brown (1978), os estudantes devem conhecer e saber sobre o próprio conhecimento: a) saber quando se sabe; b) saber o que se sabe; c) saber o que se necessita saber e d) conhecer a utilidade das estratégias de intervenção.

O desenvolvimento do conhecimento metacognitivo, de acordo com Flavell (1979) inicia-se primeiramente com a aquisição de conhecimentos cognitivos sobre a pessoa, a tarefa e as estratégias, que afetam o funcionamento cognitivo ou psicológico e, posteriormente, com as experiências metacognitivas. O referido autor explica que a variável pessoa envolve conhecimento intraindividual, interindividual e universal. A primeira refere-se ao conhecimento de si, interesses, pontos fortes e fracos, etc; a segunda diz respeito ao conhecimento sobre as diferenças entre si e os outros; por sua vez, a terceira relaciona-se ao conhecimento predominante numa cultura, que dissemina idéias e informações acerca da aprendizagem. 
A tarefa refere-se ao conhecimento produzido pelo confronto entre informação (escassa ou abundante, imprecisa ou rigorosa) e os critérios da tarefa a realizar. A informação a aprender vincula-se ao grau de familiaridade e à forma de apresentação. Por fim, a variável estratégia abrange informações sobre meios, processos ou ações que permitem atingir os objetivos com maior eficácia numa determinada tarefa. Neste sentido, é necessário possuir um repertório razoável de estratégias, bem como ter conhecimento aprofundado sobre elas.

As experiências metacognitivas relacionam ao aspecto afetivo. Abrangem impressões ou percepções conscientes que podem ocorrer antes, durante ou após a realização de uma tarefa. Essas experiências resultam, então, das dificuldades, percepções sobre a experiência cognitiva e são importantes para avaliar as próprias dificuldades e superá-las.

As estratégias de aprendizagem são as ações para resolver as ações cognitivas. Esses aspectos estão inter-relacionados total e parcialmente, isto é, podem interagir com alguns aspectos ou todos, como mostram Nisbet e Shucksmith (1986), na Figura 1.

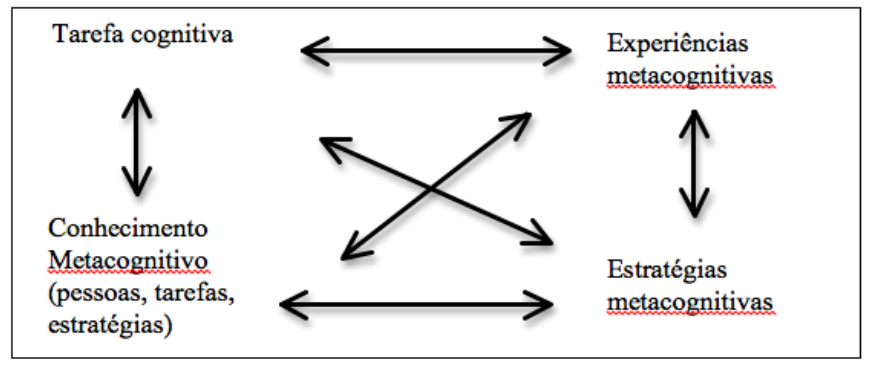

Figura 1: Relações entre tarefa, conhecimento, experiências e estratégias cognitivas Fonte: Nisbet; Shucksmith (1986)

Para Almeida (2002), as estratégias metacognitivas fundamentam-se em três funções gerais: planejamento, supervisão (ou monitoramento) e avaliação. O planejamento abrange o conhecimento da tarefa ou situação problema e o que é esperado 
do indivíduo - saber o que deve fazer; identificar os conhecimentos prévios e aqueles a serem alcançados - saber o que sabe e o que não sabe e fixar os objetivos ou metas para realização da tarefa e as estratégias adequadas, mediados pelo educador. A supervisão diz respeito ao processo ou monitoramento relacionado ao entendimento de como se pensa e se aprende, como se organiza a memória, aspectos para automotivar o comportamento, dentre outros. A avaliação, por sua vez, requer ao final da atividade a tomada de consciência sobre o quanto se aprendeu, em quanto tempo, em que condições e os ajustes necessários.

Ao considerar os padrões propostos pela Association of College and Research Library (ACRL, 2000), adaptados para esse artigo, bem como as três funções gerais das estratégias metacognitivas (ALMEIDA, 2002); o conhecimento metacognitivo sobre pessoas, tarefas e estratégias (FLAVELL, 1979) sugerem-se estratégias metacognitivas para orientar o ensino-aprendizagem de LI (Quadro 2).

Quadro 2: Estratégias metacognitivas para o letramento informacional

\begin{tabular}{|c|c|c|c|c|}
\hline $\begin{array}{l}\text { Padrões de LI } \\
\text { Estratégias }\end{array}$ & $\begin{array}{l}\text { NECESSIDADE } \\
\text { DE } \\
\text { INFORMAÇÃO }\end{array}$ & $\begin{array}{l}\text { ACESSAR A } \\
\text { INFORMAÇÃO }\end{array}$ & $\begin{array}{l}\text { USAR } \\
\text { INFORMAÇÃO }\end{array}$ & $\begin{array}{l}\text { COMUNICAR } \\
\text { A } \\
\text { INFORMAÇÃO }\end{array}$ \\
\hline PLANEJAR & $\begin{array}{l}\text { Ativar os } \\
\text { conhecimentos } \\
\text { prévios e questionar o } \\
\text { que se sabe e o que } \\
\text { não se sabe sobre o } \\
\text { assunto. } \\
\text { Identificar a } \\
\text { existência de emoções } \\
\text { em relação às tarefas } \\
\text { propostas. } \\
\text { Identificar a } \\
\text { complexidade } \\
\text { natureza da tarefa, } \\
\text { bem como os } \\
\text { conhecimentos }\end{array}$ & $\begin{array}{l}\text { Ativar os } \\
\text { conhecimentos } \\
\text { prévios sobre a busca e } \\
\text { a recuperação da } \\
\text { informação. } \\
\text { Identificar a } \\
\text { existência de emoções } \\
\text { em relação às tarefas } \\
\text { propostas e estratégias } \\
\text { de controle. } \\
\text { Listar } \\
\text { conhecimentos } \\
\text { necessários } \\
\text { realizar a tarefa. }\end{array}$ & $\begin{array}{l}\text { Ativar os } \\
\text { conhecimentos } \\
\text { prévios para } \\
\text { diagnosticar os pontos } \\
\text { positivos e negativos } \\
\text { sobre o próprio estilo } \\
\text { de organizar a } \\
\text { informação. } \\
\text { Identificar } \\
\text { sentimentos presentes } \\
\text { nessa etapa } \\
\text { trabalho de } \\
\text { estratégias } \\
\text { controle. }\end{array}$ & $\begin{array}{l}\text { Ativar os } \\
\text { conhecimentos } \\
\text { prévios sobre o } \\
\text { assunto e as lacunas } \\
\text { no conhecimento. } \\
\text { Identificar as } \\
\text { emoções presentes no } \\
\text { processo. } \\
\text { Mapear os elementos } \\
\text { que devem estar } \\
\text { presentes } \\
\text { organização } \\
\text { informação - aspectos } \\
\text { estilísticos, } \\
\text { gramaticais, }\end{array}$ \\
\hline
\end{tabular}




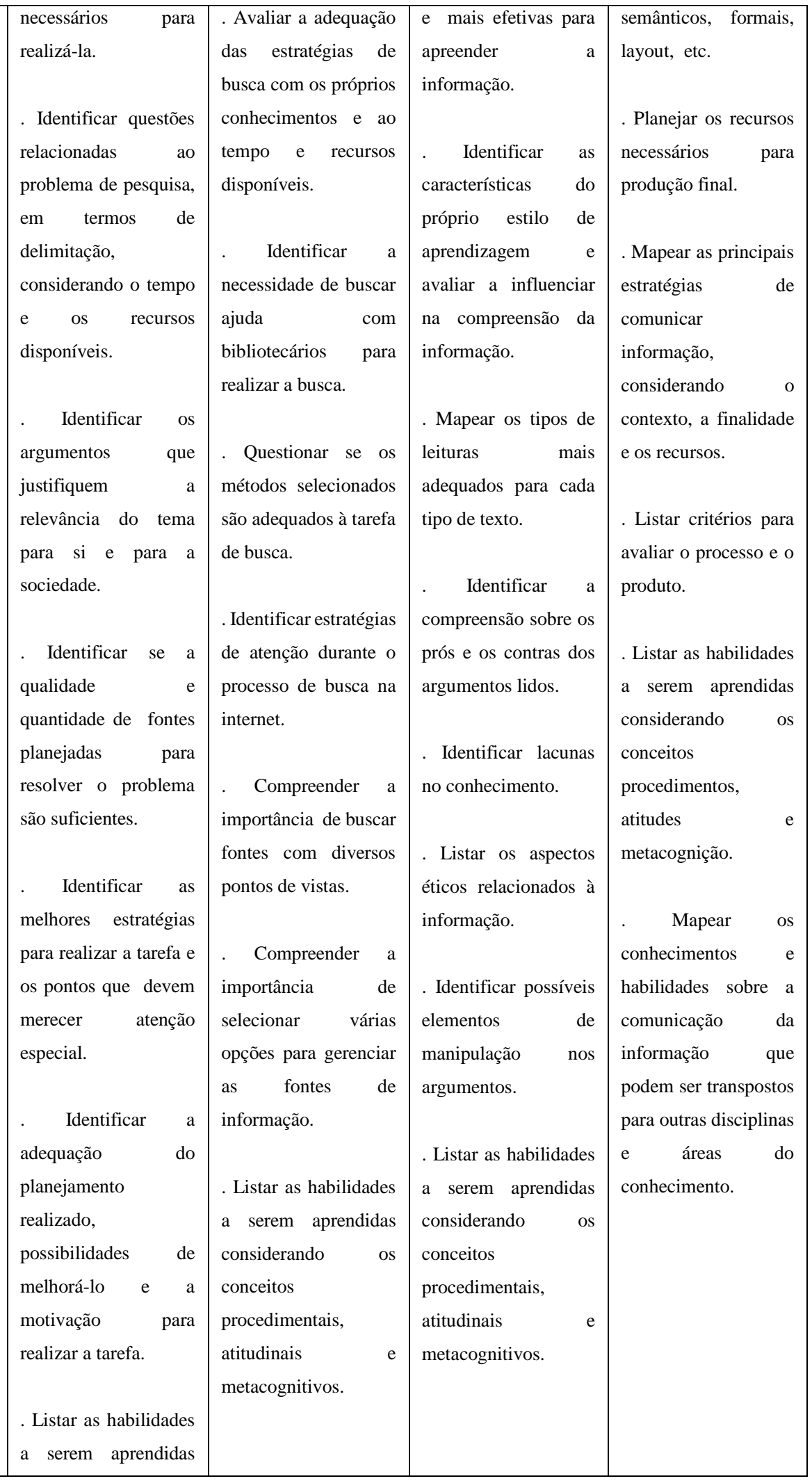




\begin{tabular}{|c|c|c|c|c|}
\hline & $\begin{array}{l}\text { considerando } \\
\text { conceitos } \\
\text { procedimentais, } \\
\text { atitudinais } \\
\text { metacognitivos. }\end{array}$ & & & \\
\hline MONITORAR & 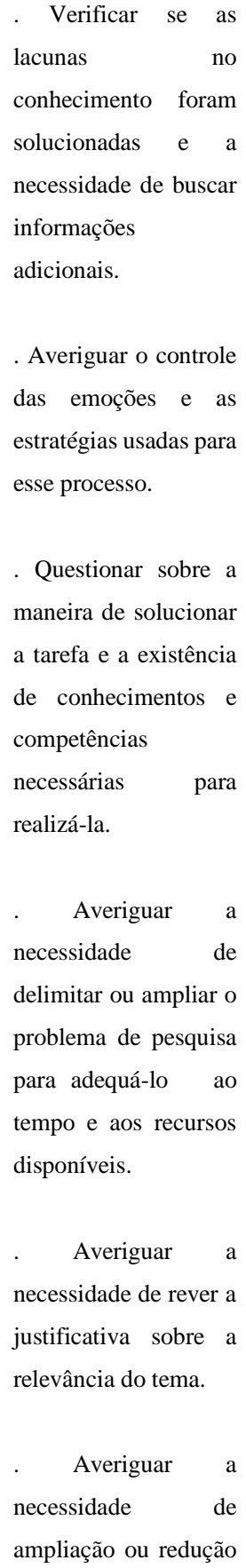 & 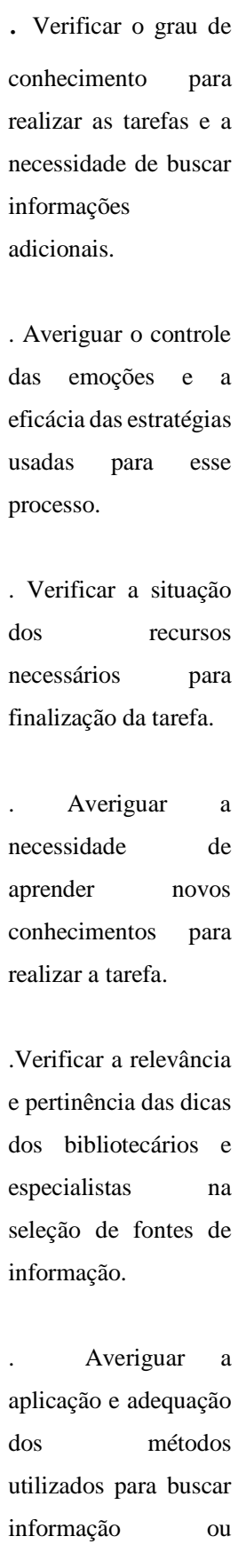 & 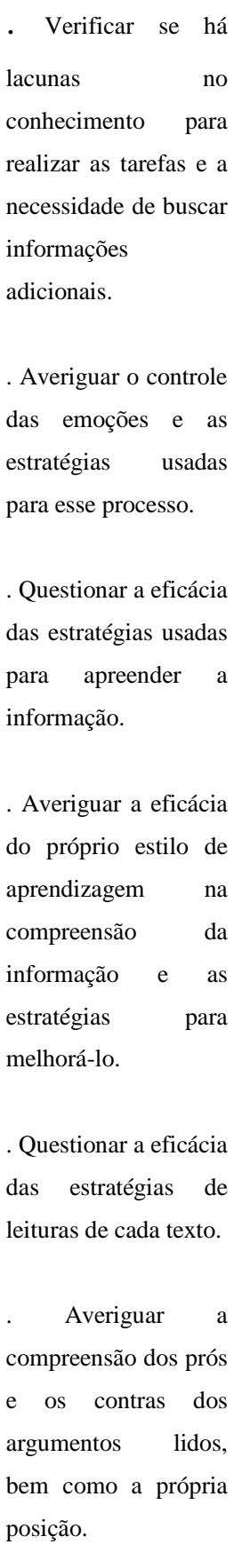 & 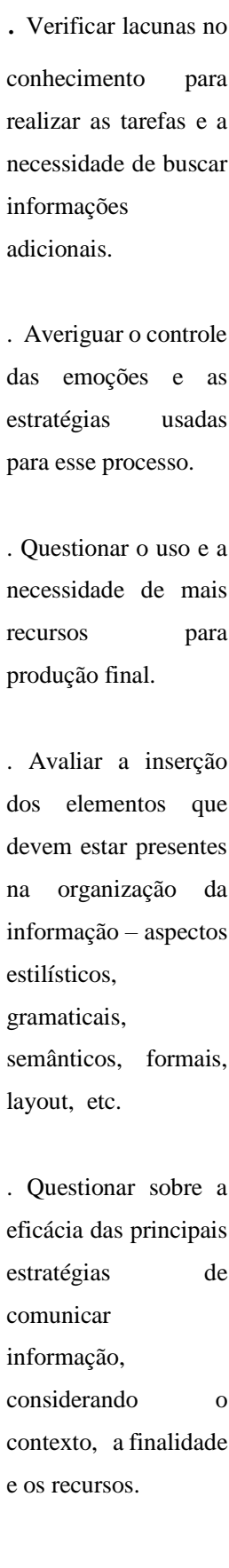 \\
\hline
\end{tabular}




\begin{tabular}{|c|c|c|c|c|}
\hline & 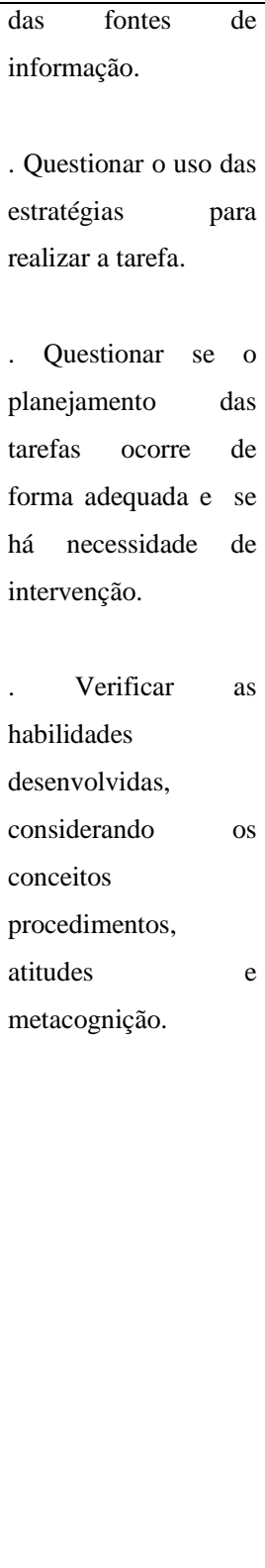 & 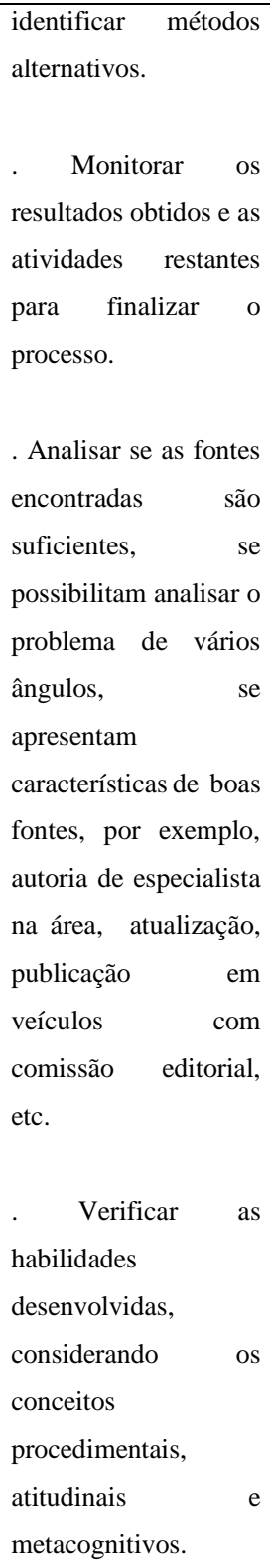 & 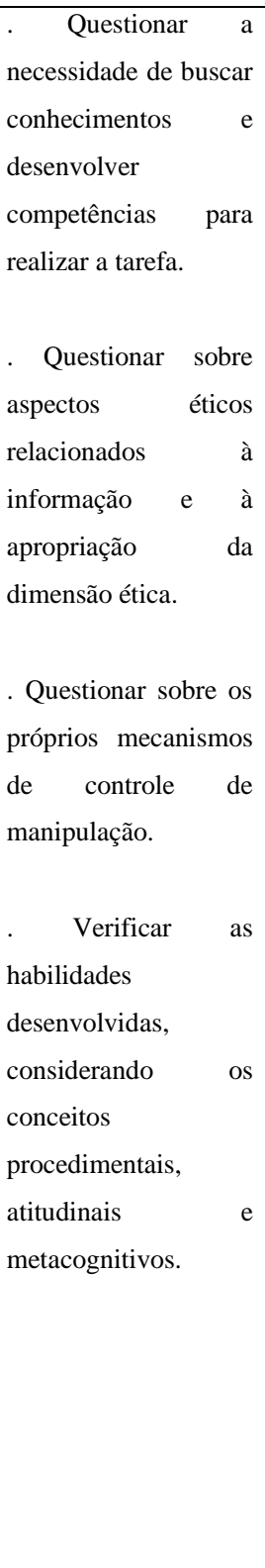 & 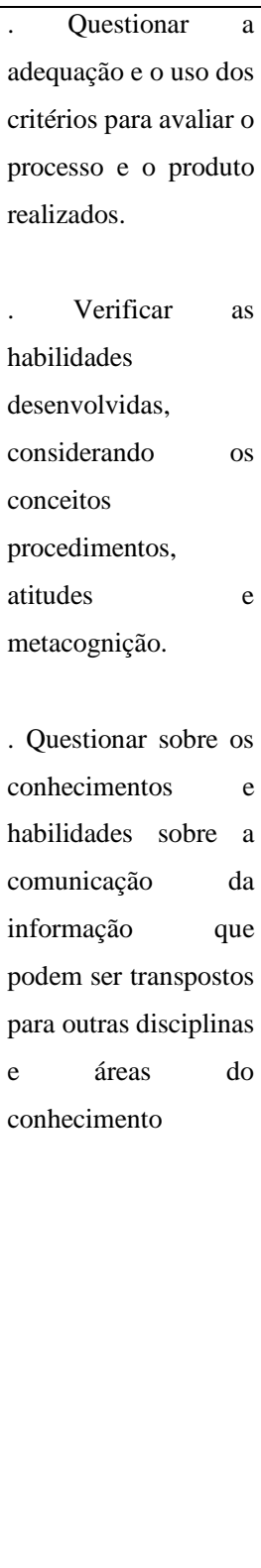 \\
\hline LAAK & $\begin{array}{l}\text { Avaliar as } \\
\text { concepções errôneas } \\
\text { ou lacunas do } \\
\text { conhecimento prévio } \\
\text { sobre o assunto. } \\
\text { Avaliar a eficácia do } \\
\text { próprio controle das } \\
\text { emoções e os }\end{array}$ & $\begin{array}{l}\text { Modificar as } \\
\text { concepções errôneas } \\
\text { ou lacunas do } \\
\text { conhecimento prévio } \\
\text { sobre o assunto. } \\
\text { Avaliar a eficácia do } \\
\text { próprio controle das } \\
\text { emoções e os }\end{array}$ & $\begin{array}{l}\text { Julgar o que se } \\
\text { aprendeu e o que é } \\
\text { necessário saber sobre } \\
\text { o assunto. } \\
\text { Avaliar a eficácia do } \\
\text { próprio controle das } \\
\text { emoções e os }\end{array}$ & $\begin{array}{l}\text { Avaliar as } \\
\text { concepções errôneas } \\
\text { ou lacunas do } \\
\text { conhecimento prévio } \\
\text { sobre o assunto. } \\
\text { Avaliar a eficácia do } \\
\text { próprio controle das } \\
\text { emoções e os }\end{array}$ \\
\hline
\end{tabular}




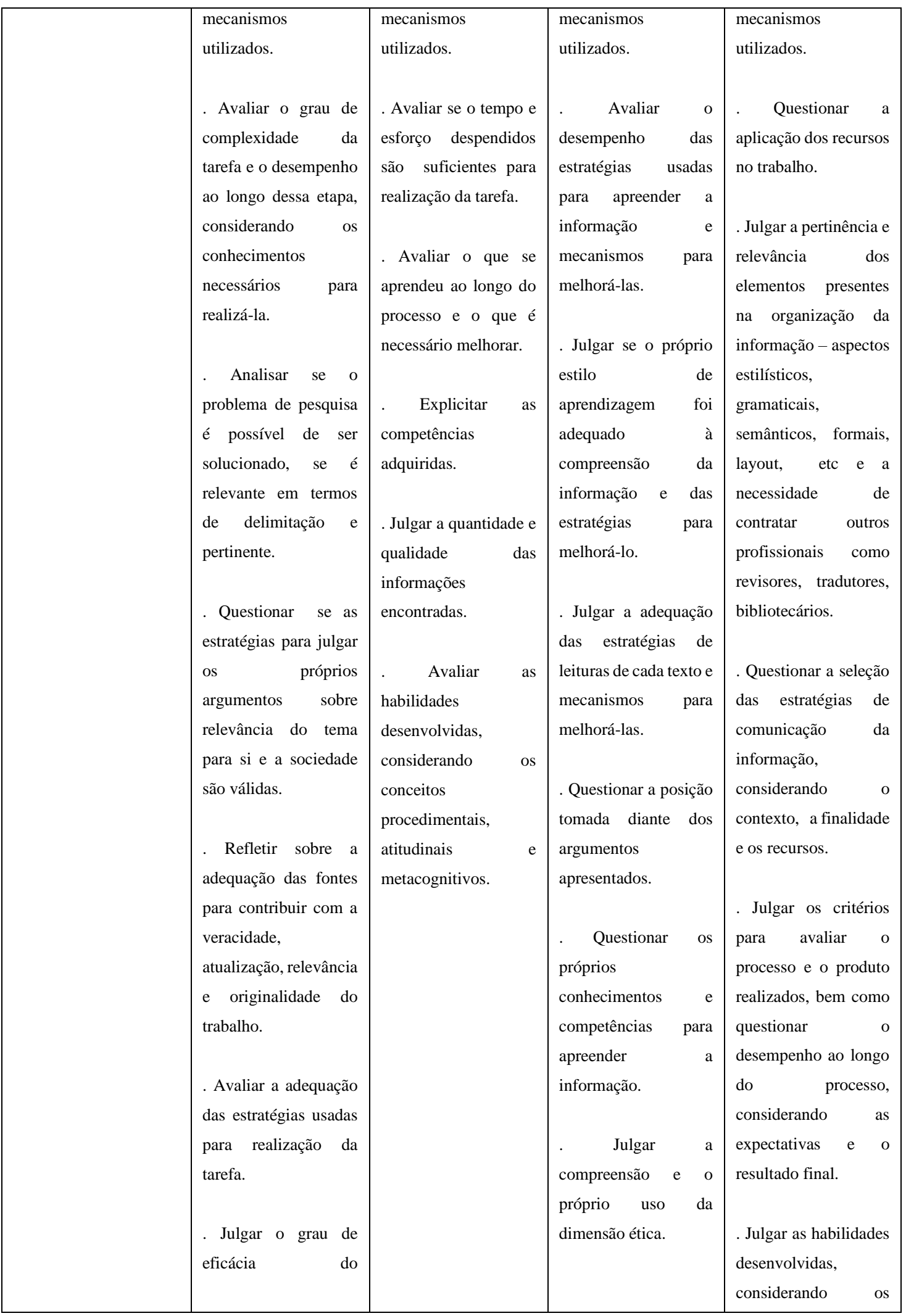




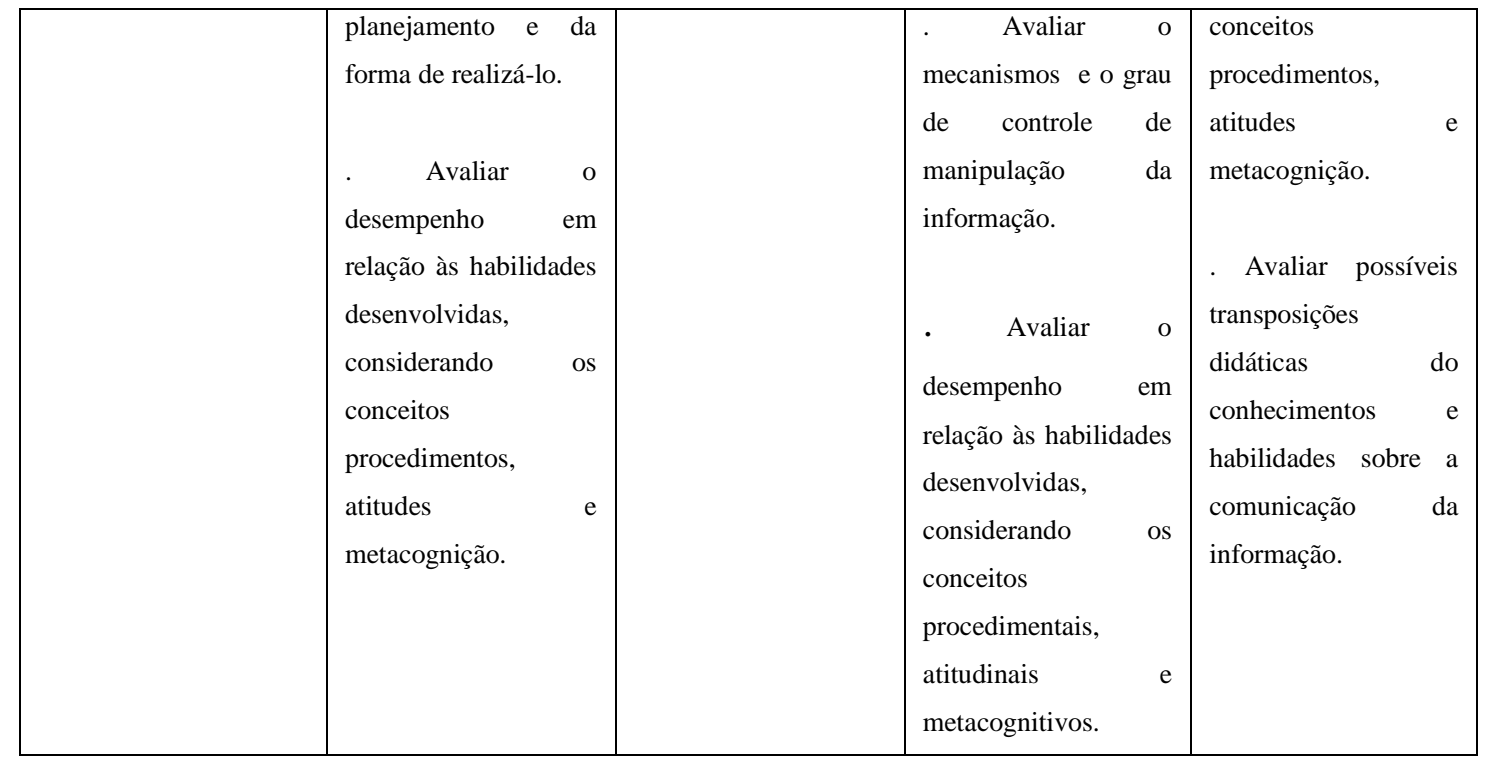

Fonte: elaboração própria

Considerando as estratégias cognitivas apresentadas, os aprendizes devem conhecer e saber sobre como e por que realizam as atividades de busca e uso da informação. Isso envolve a aprendizagem dos saberes: a) saber o que e quando se sabe sobre as próprias necessidades, o acesso, a busca e a comunicação da informação; b) saber o que se necessita saber, considerando o conhecimento prévio, as expectativas, sentimentos, os objetivos e as finalidades; e por fim, e c) conhecer a utilidade das estratégias de intervenção para melhorar o próprio processo de LI.

Ressalta-se que as estratégias metacognitivas apresentadas para o ensinoaprendizagem do LI não são absolutas e nem únicas, apenas sugestões. Devem ser utilizadas e aplicadas como um esboço para formular estratégias mais complexas e contextualizadas com as situações de ensino-aprendizagem de LI. Outras estratégias podem e devem ser usadas. Por meio das estratégias metacognitivas é possível aprimorar as próprias estratégias metacognitivas no processo de aprendizagem. Isso ocorre porque os indivíduos aprendem a automonitorar e a regular o próprio desempenho.

A aprendizagem dessas estratégias inicia-se desde a infância. Os indivíduos, em geral, repetem as estratégias que obtiveram maior eficácia. Assim, a adoção das estratégias pode ser diferentes para cada pessoa. Contudo, observa-se a relação direta 
entre a capacidade metacognitiva e as habilidades de aprendizagem, com maior otimização do tempo e da qualidade do estudo (ANDRETTA et al. , 2010).

Outro aspecto a ser destacado se refere à progressão do controle do estudante sobre as próprias ações, aumentando a aprendizagem significativa. Isto requer flexibilidade no conteúdo trabalhado e foco no estudante. Nessa perspectiva, o estudante pode avaliar a própria aprendizagem, não mais fundamentada na impressão, mas conduzida de forma realista e justa, voltada para diagnosticar as próprias limitações e possibilitar correções e ajustes. A noção de "metacognição" possibilita a auto-avaliação com maior eficácia, visto que o estudante tem a percepção do que se sabe e daquilo que não se sabe (SCALLON, 2000).

O educador deve apresentar o modelo de estratégias metacognitivas aos estudantes. Por sua vez, os aprendizes praticam e discutem as estratégias ao aprender a usá-las. Assim, o papel do educador - professores e bibliotecários - é de atuar como mediador no processo de aprendizagem do aprendiz, o que requer auxiliá-lo a refletir sobre o próprio processo de aprendizagem, a partir de situações ou tarefas apresentadas.

\section{CONSIDERAÇÕES FINAIS}

O artigo apresenta revisão de literatura sobre a metacognição no âmbito do letramento informacional. Identificaram-se poucos artigos que tratam do assunto. $\mathrm{O}$ conceito tem sido abordado na psicologia desde a década de 1960 e os primeiros estudos na ciência da informação iniciaram-se em meados da década de 1990.

As estratégias metacognitivas precisam ser consideradas como conteúdos de aprendizagem, juntamente com os padrões de LI. Essas estratégias fundamentam-se em três funções, quais sejam, planejamento, monitoração e avaliação. Os aprendizes precisam desenvolver a capacidade para refletir sobre o próprio processo de busca e uso da informação - LI - conhecer e saber sobre o quê, quando, como e por que realizam as atividades de busca e uso da informação, bem como usar as estratégias de intervenção. 
As habilidades metacognitivas podem ser ensinadas pelos educadores professores e bibliotecários - por meio de modelos nas diversas situações e tarefas que envolvem as atividades de busca e uso da informação. Tais habilidades são importantes para o letramento informacional por tornar a aprendizagem mais significativa e crítica por meio da reflexão consciente sobre os atributos cognitivos pessoais, estilo cognitivo, estratégias e conhecimento dos esquemas cognitivos.

\section{Metacognition in the process of informational literacy}

Abstract: The article presents a review of literature about metacognition in the informational literacy. The metacognition is about the knowledge of the knowledge and the control over this process. Therefore, the LI relates the learning of how to search, use and communicate the information. The analysis of the articles identifies that there are very little known about the theme, in which requires more research investments in the area, recognizing the potential of metacognition to enhace the LI learning. It is suggested metacognitive strategies for the learning of the LI standards. These metacognitive strategies are based in three main functions - planing, monitoring and evaluation. The learners need to develop the capabilities to reflect over its own ability of search and use of information - LI - to know about the what, when, how and why they realize the search and use of information's activities, as well as using intervention strategies.

Keywords: Metacognition. Information Literacy. Learning. Search and use of information.

\section{REFERÊNCIAS}

ALLUEVA, P. Conceptos básicos sobre metacognição. In:

Programa de

Intervéncion. Zaragosa. Consejeria de Educacion y Ciência. Disputación General de Aragon, 2002.

ALMEIDA, Miriam de Abreu. Estratégias metacognitivas: uma possibilidade no ensino de enfermagem. Rev. Bras. Enferm., Brasília, v. 55, n. 4, p. 424-429, jul./ago. 2002 . Disponível em:< http://www.lume.ufrgs.br/bitstream/handle/10183/101525/000353843.pdf?sequence=1 $>$ . Acesso em: 26 . set. 2016.

ANDRETTA, Ilana et al. Metacognição e Aprendizagem: como se relacionam? PSiCo, Porto 
Alegre, PUCRS, v. 41, n. 1, pp. 7-13, jan./mar. 2010. Disponível em: <https://dialnet.unirioja.es/descarga/articulo/5161456.pdf>. Acesso em: 02 ago. 2016.

ASSOCIATION OF COLLEGE AND RESEARCH LIBRARY - ACRL. Information Literacy Competency Standards for Higher Education. Chicago: ALA, 2000. Disponível em : <http://www.ala.org/acrl/standards/informationliteracycompetency>. Acesso em: 21 out. 2016.

BOWLER, Leanne. A taxonomy of a adolescent metacognitive knowlwdge during information search process. Library and information Science Research, v. 32, p. 27-42, 2010.

BRANSDSFORD, J. D.; BROWN, A. L.; COCKING, R. R. (Org.). Como as pessoas aprendem: cérebro, mente, experiência e escola. São Paulo: SENAC, 2007.

BROWN, Ann. L. Knowing when, where, and how to remember: A problem of meta-cognition. In: R. Glaser (ed.), Advances in instructional psychology, v. 2, p. 77-165. Hillsdale: Erlbaum, 1978.

BUDD, John; LLOYD, A. Theoretical foundations for information literacy: A plan for action. Proceedings of the ASIS annual meeting, v. 51, n.1, p. 1 - 5, 2014.

CORDEIRO, Alexander Magno et al. Revisão sistemática: uma revisão narrativa. Revista do Colégio Brasileiro de Cirurgiões, Rio de Janeiro, v. 34, n. 6, p. 428-431, nov./dez. 2007. Disponível em: 〈http://www.scielo.br/pdf/rcbc/v34n6/11.pdf〉. Acesso em: 07 Jun. 2016.

DANTAS, Cláudia; RODRIGUES, Camila Cruz. Estratégias metacognitivas como intervenção psicopedagógica para o desenvolvimento do automonitoramento. Rev. psicopedag., São Paulo , v. 30, n. 93, p. 2026-2035, 2013. Disponível em $<$ http://pepsic.bvsalud.org/scielo.php?script=sci_arttext\&pid=S010384862013000300009\&lng=pt\&nrm=iso>. Acesso em: 25 set. 2016.

FLAVELL, John H. Metacognition and cognitive monitoring: a new area of cognitivedevelopmental inquiry. American Psychologist, v.34, n. 10, p.906-911, 1979.

GASQUE, Kelley Cristine Gonçalves Dias. Letramento informacional: pesquisa, reflexão e aprendizagem. Brasília: Faculdade de Ciência da Informação, 2012. 178 p.

JACOBSON, Trudi; O'KEEFFE; Emer. SEEKING-AND FINDING-Authentic Inquiry Models for Our Evolving Information Landscape. Knowledge Quest, v. 43, n.2; p. 26-33, 2014.

MADDEN, Andrew et al. Metacognition and web credibility .The Electronic Library, 2012, v. 30, n. 5, p. $671-689$.

METCALFE, Janet; SHIMAMURA, Arthur. Metacognition: knowing about knowing. Cambridge: Massachusetts Institute of Technology, 1994. 
NISBET, John D.; SHUCKSMITH, Janet. Learning Strategies. London: Routledge \& K. Paul, 1986.

PERRAUDEAU, Michel. Estratégias de aprendizagem: como acompanhar os alunos na aquisição dos saberes. Porto Alegre: Artmed, 2009.

PORTILHO, Evelise Maria Labatut. As estratégias metacognitivas de quem aprende e de quem ensina. In: Aprendizagem. Petrópolis: Vozes. 2006, p. 47-59. Disponível em: < http://www.metacognicao.com.br/wp-content/uploads/2013/03/As-estratégiasmetacognitivas-de-quem-aprende-e-de-quem-ensina.pdf >. Acesso em: 26 set. 2016.

RIBEIRO, Célia. Metacognição: um apoio ao processo de aprendizagem. Psicologia: Reflexão e Crítica, v.16, n. 1, p. 109-116, 2003. Disponível em: <http://www.scielo.br/pdf/prc/v16n1/16802.pdf. >. Acesso em: 25 set. 2016.

RIBEIRO, Célia. Aprender a Aprender: algumas considerações sobre o ensino de estratégias de estudo. Máthesis, n. 11, p. 273-286, 2002.

SANTAMARIA, Michele ; PETRIK, Denise Cornering the Information Market: Metacognition and the Library. College \& Research Libraries News, v. 73, n. 5, p.265-266, May 2012.

SCALLON, G. Avaliação formativa e psicologia cognitiva: correntes e tendências. In: GRÉGOIRE, J. Avaliando as aprendizagens - os aportes da psicologia cognitiva. Porto Alegre: Artmed, 2000.

STEDILE, Nilva; FRIENDLANDER, Maria Romana. Metacognição e ensino de enfermagem: uma combinação possível? Revista latino-americana de enfermagem, v. 11, n.6, Nov/Dez. 2003.

Agradecimento ao Breno Paulinelli pela correção do abstract.

\section{Informações da autora}

\section{Kelley Cristine Gonçalves Dias Gasque}

Universidade de Brasília - Faculdade de Ciência da Informação

Doutorado e mestrado em Ciência da Informação

Membro do Programa de Pós-Graduação da Ciência da Informação

Coordenação do curso de Biblioteconomia

Kelley@unb.br - (61) 3107-2635

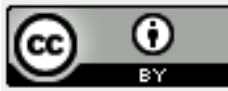

